\title{
Family Conflict and Violence by Persons with Serious Mental IIIness: How Clinicians Can Intervene During the COVID-19 Pandemic and Beyond
}

\author{
Travis Labrum $^{1} \cdot$ Christina Newhill $^{1} \cdot$ Peter Simonsson $^{2} \cdot$ Ana T. Flores $^{1}$ \\ Accepted: 3 December 2021 / Published online: 11 January 2022 \\ ( ) The Author(s), under exclusive licence to Springer Science+Business Media, LLC, part of Springer Nature 2022
}

\begin{abstract}
Although most persons living with serious mental illness (SMI) do not act violently, this population is at a modestly increased risk of engaging in violence, with family members being the most common victims. Consequently, evidence suggests that a sizable minority of family members-many of whom are caregivers - have experienced violence by their relative with SMI. The risk of conflict and violence in families of persons with SMI is likely currently heightened due to a range of challenges resulting from the COVID-19 pandemic (e.g., interruption in treatment services and the occurrence of arguments while sheltering in place together). As such, during the pandemic, it is particularly important that clinicians intervene with these populations to prevent conflict and violence and strengthen their relationships with each other. Based on available evidence, we recommend that clinical interventions aiming to do so address the following topics with family members and/or persons with SMI: mutual understanding; positive communication; effective problem-solving; symptoms and psychiatric crises; triggers to, and early warning signs of, anger and conflict; and strategies for de-escalating conflict and managing violent behavior. We offer suggestions for how clinicians can address these topics and recommend established clinical resources providing more guidance in this area.
\end{abstract}

Keywords Caregiving $\cdot$ Aggression $\cdot$ Schizophrenia $\cdot$ Psychiatric disorder $\cdot$ Family psychoeducation

Most persons with serious mental illness (SMI)—defined as mental disorders such as schizophrenia and bipolar disorder resulting in substantial functional impairments-do not engage in violence (Fazel et al., 2009, 2010), with members of this population being more likely to be victims than perpetrators of violence (Desmarais et al., 2014). However, persons with SMI are at a modestly increased risk of engaging

Travis Labrum

tr151@pitt.edu

Christina Newhill

newhill@pitt.edu

Peter Simonsson

peter.simonsson@temple.edu

Ana T. Flores

atf26@pitt.edu

1 School of Social Work, University of Pittsburgh, Pittsburgh, USA

2 Lewis Katz School of Medicine, Temple University, Philadelphia, USA in violent acts (Fazel et al., 2009, 2010; Fleischman et al., 2014), particularly when more proximal violence risk factors are present (e.g., substance use, antisocial traits, and history of violence). In contrast to only $21 \%$ of violence by the general population targeting family members (Truman \& Morgan, 2014), half of all violence by persons with SMI occurs toward such persons (Binder \& McNeil, 1986; Estroff et al., 1998; Monahan et al., 2001). As a result, a sizable minority of family members, many of whom are providing care to persons with SMI, have likely feared (Katz et al., 2015; Labrum \& Solomon, 2018) or experienced violence by their relative with SMI. Unfortunately, studies utilizing representative samples have yet to examine the prevalence of family violence by this population. However, most extant studies on this topic - all of which have utilized convenience sampling - have found approximately $20 \%$ of caregivers and other family members with high levels of contact with persons with SMI to have experienced violence by their relative with SMI in the past year (for a review see Labrum \& Solomon, 2017). Family violence by persons with SMI has a range of noxious consequences for family members-such 
as psychological distress, trauma symptoms, and possible injury and death (Ahn et al., 2012; Onwumere et al., 2018) - and for persons with SMI, including involvement in the criminal justice system and deteriorated relationship quality and disconnection from family members (Kageyama et al., 2018, 2019; Labrum \& Solomon, 2022; Onwumere et al., 2019).

Emerging evidence suggests that in the COVID-19 pandemic, family violence is increasing among the general population (Boserup et al., 2020). Such violence is likely also increasing in families that include a member with SMI (rationale provided in the next section). As such, it is especially critical during the COVID-19 pandemic, that practitioners working with persons with SMI and/or their families intervene to prevent family conflict and violence and to otherwise improve relationship quality. In this article, we summarize the two primary explanations recently proposed in a review of the literature (Labrum et al., 2021) as to why persons with SMI may be at an enhanced risk of engaging in violence toward family members. Based on these explanations and available evidence, we offer recommendations for clinical interventions aiming to prevent family violence by this population and references to established resources that may be helpful to clinicians in this effort. We present a composite case vignette to illustrate the two primary explanations for the occurrence of this phenomenon and the potential benefits of utilizing recommended clinical interventions.

\section{Explanations for Family Violence by Persons with SMI and COVID-19}

While an extensive research literature exists examining violence by persons with SMI, the overwhelming majority of such studies have not ascertained the relationships of persons with SMI and victims of violence and/or have failed to specifically examine violence toward family members. As a result, a relatively limited number of studies have examined violence by persons with SMI specifically toward family members. Nearly all such quantitative studies have examined risk and protective factors related to the occurrence of this phenomenon, with most factors pertaining to persons with SMI and their interactions with family members (for reviews see Labrum \& Solomon, 2015; Solomon et al., 2005). Synthesizing the results of these and extant qualitative studies, Labrum et al. (2021) argue that persons with SMI may be more likely than the general population to engage in violence toward family members for two often-overlapping reasons. First, some persons with SMI, in specific contexts, have an increased vulnerability to engaging in violent acts related to experiencing specific psychiatric symptoms (e.g., threat/ control-override symptoms of psychosis) and other illnessrelated symptoms (e.g. comorbid substance use conditions and impairments in emotion regulation and neurocognition). Such characteristics are known to increase the risk of violence by persons with SMI regardless of relation to victims (Newhill et al., 2012; Reinharth et al., 2014; Witt et al., 2013), and likely have the same impact on the likelihood of violence toward family members. In additional support of this argument, use of psychiatric medications and regular attendance of mental health treatment - which may help decrease and/or manage aforementioned vulnerabilities to violent behavior-are known to lessen the risk of violence by persons with SMI toward community (Witt et al., 2013) and family members alike (Kivisto \& Watson, 2016; Labrum $\&$ Solomon, 2016). Similarly, qualitative studies reveal that many family members perceive violence by persons with SMI to be connected to psychotic symptoms, episodes of acute psychiatric symptoms, medication non-adherence, and ineffective/inadequate treatment experiences (Askola et al., 2017; Copeland \& Heilemann, 2011; Kageyama et al., 2018; Sporer et al., 2019).

In the Family Violence Perspective, conflict among family members is considered universal, resulting from unavoidable discrepancies in "personal agendas"-goals, desires, and preferences-among family members (Gelles \& Straus, 1979; Straus, 1979). Verbal and physical aggression are considered methods of resolving discordant personal agendas. Aggression can be engaged in by both parties and, in agreement with Resource Theory, is more likely to be utilized when parties have fewer resources to advance their preferences (Allen \& Straus, 1980). Discrepancies in goals, desires, and preferences and other stressors damage relationship quality and lead to events in which verbal aggression escalates to violence after failing to resolve the conflict (Strauss, 2011). ${ }^{1}$ The second reason proposed as to why persons with SMI may be at greater risk of engaging in family violence is that this process of violence (i.e., discrepant personal agendas lead to conflict and violence) may be experienced more frequently in families that include a member with SMI. Many family members provide considerable

\footnotetext{
${ }^{1}$ Based on available evidence, we and Labrum et al. (2021) consider the Family Violence Perspective to be a helpful, broad theory for understanding violence by persons with SMI toward family members. Similar to Frustration-Aggression Theory (Dollard et al., 1939) being a general theory of aggression/violence, the Family Violence Perspective is a general theory of family violence able to be applied to various family relationships (intimate partners, siblings, etc.), which additional theories (e.g., Social Learning Theory) may be compatible with and augment. Feminist scholars have long criticized applying the Family Violence Perspective to the phenomenon of violence by men toward female intimate partners; debate continues, and scholarship conducted in this area during the past two decades has increasingly considered types of intimate partner violence that may be best explained by Feminist Theory vs. the Family Violence Perspective (Johnson, 2008; Love et al., 2020).
} 
levels of instrumental and financial support to their relative with SMI (National Alliance for Caregiving, 2016). Providing this care often leads to financial, psychological, and social burdens (Awad \& Voruganti, 2008; Labrum, 2018), which can place stress on the relationships between persons with SMI and their family members. Such stress may, in turn, result in family members, at specific times, relating to persons with SMI with negative expressed emotion: hostility, criticism, and emotional overinvolvement (Wearden et al., 2000). More notably, persons with SMI being dependent on family members for housing, financial aid, and other forms of support not only increases family contact-and thereby opportunities for conflict-but can be connected to family members supervising persons with SMI and attempting to modify their behaviors, termed limit-setting practices (Labrum et al., 2016). Family members may perceive that engaging in limit-setting practices is in their relatives' best interest; however, when limit-setting practices are utilized, the immediate personal agendas of family members and persons with SMI are inherently discordant, and engaging in limit-setting practices may contribute to the process of family violence described above. In support of this argument, family members setting limits with persons with SMI is one of the variables most repeatedly found to be connected to family violence by this population (Ahn et al., 2012; Labrum, 2017; Labrum \& Solomon, 2016; Straznickas et al., 1993; Varghese et al., 2016). Other identified risk factors for the occurrence of this phenomenon that provide support for the arguments in this paragraph include various forms of caregiving, premorbid poor relationship quality, high levels of contact with family members, negative expressed emotion, and the presence of psychological abuse (Elbogen et al., 2005; Estroff et al., 1998; Labrum, 2017; Labrum \& Solomon, 2016; Smith et al., 2018; Vaddadi et al., 2002).

Although psychiatric and other illness-related symptoms of persons with SMI may lead to acts of family violence through different processes (e.g., acting violently in response to acute symptoms of paranoia, without an escalation of reality-based conflict), these symptoms are often connected to acts of family violence through contributing to the process of escalating conflict focused on discrepancies in personal agendas described above. Later in the paper, we provide a composite case vignette in which an act of violence by an adult with schizophrenia toward his mother is connected to both experiencing psychotic symptoms and an escalation of conflict centered on discordant personal agendas.

Like family violence among the general population increasing during the COVID-19 pandemic (Boserup et al., 2020), the risk of family violence by persons with SMI is likely also enhanced. Substance use and symptoms that can elevate the likelihood of violence may be exacerbated during the pandemic, due to persons with SMI experiencing interruptions in treatment services, loneliness resulting from social distancing, and additional stressors (Czeisler et al., 2020; Hamada \& Fan, 2020). Persons with SMI often live with family members, and shelter in place requirements are likely resulting in these parties spending considerably more time together, creating additional opportunities for conflicts related to discordant personal agendas to occur. Finally, due to experiencing increased stress, both parties may experience additional difficulties coping with conflicts and preventing them from escalating to violence.

\section{Intervening to Prevent Family Violence by Persons with SMI}

Unfortunately, the effectiveness of clinical interventions in preventing aggression by persons with SMI toward family members have yet to be studied in the U.S. Internationally, however, two interventions have demonstrated promise in this area. In Taiwan, Sun and Hsu (2016) delivered an intervention to both persons with SMI and their parents, which addressed the behavioral and cognitive process of behaviors and behavior management, communication skills, problemsolving, potential connections between psychiatric symptoms and violence, and de-escalation techniques. Utilizing a randomized controlled trial, they found the intervention to effectively decrease aggression by persons with SMI. In Japan, Kageyama et al. (2020) developed a brief video-based intervention delivered only to family members, which primarily focused on exposing participants to the experiences of other family members and persons with schizophrenia regarding family violence, aiming to promote communication and mutual understanding between persons with schizophrenia and their parents. Providing tentative support for the intervention's effectiveness, using a pretest-posttest group design it was found that the frequency of violent behaviors by persons with schizophrenia decreased upon completion of the program.

Based on the two primary explanations for family violence by persons with SMI provided and the results of these studies, we recommend that clinical interventions aiming to prevent the occurrence of this phenomenon address the following topics with family members and/ or persons with SMI, as feasible: mutual understanding; positive communication; effective problem-solving; symptoms and psychiatric crises; triggers to, and early warning signs of, anger and conflict; and strategies for de-escalating conflict and managing violent behavior. Assisting family members and persons with SMI in addressing symptoms and psychiatric crises is most likely to help prevent family violence through decreasing, managing, and/or remediating symptoms of persons with SMI which can contribute to violence. Addressing remaining recommended topics is most likely to lessen 
the likelihood of family violence through strengthening the abilities of family members and persons with SMI to prevent, manage, and/or resolve conflicts regarding discrepancies in goals, desires, and preferences. These topics are addressed in established family psychoeducation models and/or various cognitive-behavioral interventions designed to prevent community and family violence by other populations. Family psychoeducation models are cognitive-behavioral interventions most commonly provided to both family members and persons with SMI, aiming to help relatives cope with family challenges and to decrease symptoms and hospitalization rates among persons with SMI (Harvey, 2018). Although family psychoeducation models have yet to be tested regarding preventing family violence, they are robustly documented to produce a range of beneficial impacts for persons with SMI and their family members (Lucksted et al., 2012). An attractive component of family psychoeducation interventions is their strengths-based orientation. In addressing the recommended topics, clinicians should routinely assess for strengths and guide parties in recognizing, further utilizing, and expanding on these strengths. Given the need for social distancing during the COVID-19 pandemic, in many circumstances, services addressing these topics will need to be provided via remote technology (i.e., internet or telephone). In support of delivering such services via remote technology, available evidence indicates that psychosocial services delivered via the internet to persons with SMI and their family members can be effective (Haselden et al., 2019; Kaplan et al., 2014; Rotondi et al., 2010). Below, we provide guidance regarding addressing recommended topics with persons with SMI and/or their family members, along with references to established resources that may be of assistance in doing such. As a visual aid, these recommendations and resources are listed more briefly in Table 1.

\section{Mutual Understanding Among Persons with SMI and Family Members}

To foster this goal, in a time when parties are not experiencing conflict, it may be important to support parties sharing with each other (as they feel comfortable) their perceptions and experiences regarding the causes, incidents, and consequences of conflict and aggression and to validate each other's perspectives/experiences. If services are only being delivered to one party, it may be beneficial to use role-plays and/or mental imagery exercises to support clients in further developing empathy for the other party. (Substance Abuse and Mental Health Services Administration [SAMHSA], 2009).

\section{Positive Communication}

The basis of many family conflicts involves a breakdown in communication (Hsu \& Tu, 2014). Educating family members that many persons with SMI have enhanced sensitivity to stimulation-including verbal communication-can be helpful. If family members are observed as interacting with their relative with SMI with hostility, criticism, and/ or emotional overinvolvement, it may be helpful for these behaviors to be reframed as being the result of feelings of genuine concern, frustration, and/or helplessness. It may be helpful to support family members and persons with SMI in conveying warmth (e.g., concern and empathy), positive regard, and appreciation in their communication with each other. In an effort to help parties prevent escalating arguments, it is important to support parties in communicating in a calm manner, expressing feelings with "I messages", providing brief explanations as to why feelings are experienced (to assist the other party in understanding their perspective), describing observations matter-of-factly (without judgement), and making clear, specific requests focused on desired actions (as opposed to offering criticism of problematic actions). (Kolko et al., 2011; Interpersonal Effectiveness modules of Linehan, 2014; SAMHSA, 2009; Wexler, 2020).

\section{Effective Problem-Solving}

It may be helpful to educate parties on the structured problem-solving process, i.e., define the problem, list possible solutions, identify advantages and disadvantages of possible solutions, choose a solution, create an action plan, and review implementation. Once these steps are understood, the clinician can engage parties in participating in the structured problem-solving process related to a myriad of concerns, which may pertain to psychiatric symptoms, illness-related behaviors, and household duties (completing chores, etc.). In defining the problem, it may be helpful for family members to reevaluate their expectations of their relatives with SMI. Similarly, it may be helpful to assist parties in classifying problem behaviors as "annoying" vs. "dangerous", with dangerous problem behaviors greater necessitating solutions and, possibly, justifying the use of solutions that may not be jointly agreed upon (e.g., calling police when fearing for one's life). As part of the problem-solving process, it may also be helpful to educate family members on providing reinforcements and punishments with particular emphasis on recognizing and rewarding desired behaviors and calibrating punishments in response to the severity of the problem. Parties should be recommended to complete the structured problem-solving process outside of sessions (with review of this process possibly occurring in sessions), to increase the likelihood that they will continue to utilize the structured 
Table 1 Topics/strategies recommended to be addressed with persons with SMI and/or their family members to prevent family conflict and violence

Mutual understanding

-Support family members and persons with SMI sharing with each other (as they feel comfortable) their perceptions \& experiences regarding incidents of conflict and aggression

- Support parties in considering each other's perspectives/experiences, possibly utilizing role-plays and/or mental imagery

Resource for additional information: Substance Abuse and Mental Health Services Administration ([SAMHSA] 2009)

Positive communication

-Educate family members on enhanced sensitivity to verbal stimulation among many persons with SMI

-Reframe possible hostility, criticism, and emotional overinvolvement as feelings of frustration and helplessness

- Support parties in conveying warmth, positive regard, and appreciation

-Support parties in communicating in a calm manner; expressing feelings with "I messages"; providing brief explanations as to why feelings are experienced; describing observations matter-of-factly; and making clear, specific requests focused on desired actions

Resources for additional information: Kolko et al. (2011); Interpersonal Effectiveness modules of Linehan (2014); SAMHSA (2009); Wexler (2020)

Effective problem-solving

-Educate parties on structured problem-solving process

-Assist family members in classifying problem behaviors as "annoying" vs. "dangerous" and, possibly, reevaluating expectations of their relative with SMI

-Supporting family members in rewarding desired behaviors and calibrating punishments in response to severity of the problem

-Engage parties in participating in the structured problem-solving process related to family concerns, in and outside of treatment services

Resource for additional information: Kolko et al. (2011); SAMHSA (2009)

Psychiatric symptoms and crises

-Educate parties on common psychiatric and other illness-related symptoms

- Support parties in accessing local treatment services, especially those corresponding to specific symptoms present in persons with SMI that

may increase risk of violence (e.g. substance use treatment, Social Cognition Training, Cognitive Behavioral Therapy for psychosis)

-Aid parties in identifying early warning signs of psychiatric crises

- Assist parties in creating a psychiatric crisis management plan, possibly including a psychiatric advance directive

Resources for additional information: SAMHSA, 2009, 2019

Triggers and early warning signs of anger and conflict

-Educate parties on the cognitive-behavioral model of problematic behaviors (including role of cues and cognitions)

- Solicit perceptions from parties regarding triggers and early warning signs of anger and conflict

-Educate parties on common triggers and warning signs of anger and conflict

Resources for additional information: Kolko et al. (2011); Chain Analysis of Problem Behaviors modules of Linehan (2014); Reilly et al. (2019); Wexler (2020)

De-escalating conflict and managing violent behavior

-Solicit perceptions from parties regarding effective de-escalation strategies within the cognitive-behavioral model of problematic behaviors

-Reinforce opportunities for de-escalation

-Educate parties on strategies commonly recommended for preventing and de-escalating conflict

-Inform parties of local resources to manage violent behavior (e.g. CIT trained officers and mobile crisis and domestic violence advocate services)

- Assist parties in creating a written conflict management plan, including

-Coping strategies to be used to remain calm when experiencing triggers to anger and violence

-Support persons to contact to help manage conflict/violence

-Support persons to NOT contact, who may enflame conflict/violence

-When to contact the police vs. alternative professionals (e.g. crisis psychiatric services)

-Agreement of consequences to future violence

Resources for additional information: Kolko et al. (2011); Chain Analysis of Problem Behaviors modules of Linehan (2014); Reilly et al. (2019); Wexler (2020)

problem-solving process when no longer receiving treatment services. (Kolko et al., 2011; SAMHSA, 2009).

\section{Symptoms and Psychiatric Crises}

As conflict and violence is often connected to the presence of illness-related characteristics and family members' attempts to manage these characteristics, parties should be educated on common psychiatric and other illness-related symptoms. Navigating the mental health treatment system is a challenge for many family members and persons with SMI, including in periods of psychiatric crisis. They should be educated on local treatment services (including crisis response teams, crisis "hotlines", peer-run "warmlines" etc.), and supported in accessing such services, which may help manage symptoms that can contribute to violence. Evidence suggests that various forms of cognitive-behavioral therapy delivered to persons with SMI can be effective in reducing violence and aggression by persons with SMI (Rampling et al., 2016), likely by focusing on reducing 
cognitive and affective symptoms contributing to the risk of violence. When persons with SMI have such symptoms, parties should be supported in accessing related treatment services. Similarly, persons with SMI with impairments in social cognition and/or antisocial values/traits, should be supported in engaging in treatments such as Social Cognition and Interaction Training and Reasoning \& Rehabilitation programs, which evidence suggests can decrease the risk of violence by this population (Darmedru et al., 2017). Finally, the presence of substance use conditions considerably increases the risk of violence by persons with and without SMI (Fazel, 2009; Whiting et al., 2020); persons with comorbid SMI and substance use disorders and their family members should be supported in accessing evidence-based substance use services. Family members and persons with SMI should also be assisted in identifying early warning signs of psychiatric crises and in creating a psychiatric crisis management plan. The creation of such a plan should involve both parties and may include creating a formal psychiatric advance directive. (SAMHSA, 2009, 2019).

\section{Triggers to, and Early Warning Signs of, Anger and Conflict}

Understanding the triggers and early warning signs of anger and conflict involves educating the parties on the cognitivebehavioral model of problematic behaviors (focusing on the role of cues and cognitions). It is important to solicit perceptions from each party regarding triggers and warning signs, as their perceptions may differ. Further, exploring the perceptions of both parties, especially regarding the role of cognitions in experiencing anger, may help involved persons further develop empathy for one another. It may also be helpful to educate parties on common triggers and warning signs of anger and conflict, including cognitions related to being disrespected or treated with ill intent, having a duty to protect one's honor, or being justified in acting violently. (Kolko et al., 2011; Chain Analysis of Problem Behaviors module of Linehan, 2014; Reilly et al., 2019; Wexler, 2020).

\section{De-Escalating Conflict and Managing Violent Behavior}

Also utilizing the cognitive-behavioral model of problematic behaviors, practitioners are advised to solicit perceptions from parties regarding effective de-escalation strategies, reinforce opportunities for de-escalation, and educate parties on strategies commonly recommended for preventing and de-escalating conflict. Such strategies may include engaging in coping techniques when cognitive triggers to anger and conflict occur (e.g., reminding oneself of disputing cognitions and engaging in activities with the intent of producing distraction or relaxation), communicating calmly, proposing the use of a "time-out" from the argument, respecting proposals by the other party to engage in a "time-out", and, if necessary, quickly removing oneself from the setting. It may be important to inform parties of local resources to manage and respond to violent behavior (e.g., CIT trained officers and mobile crisis and domestic violence advocate services). Assisting parties in creating, and potentially agreeing upon, a written conflict management plan during a period without conflict would include documenting coping strategies to be used to remain calm when triggers to anger and violence are experienced, actions to be taken to de-escalate conflict and prevent violence once conflict has ensued, support persons to contact to help manage conflict/violence; support persons to NOT contact, who may enflame conflict/violence; when to contact the police vs. alternative professionals (e.g. mobile crisis services); and a mutually acceptable agreement regarding the consequences of future violence. (Kolko et al., 2011; Chain Analysis of Problem Behaviors module of Linehan, 2014; Reilly et al., 2019; Wexler, 2020).

\section{Composite Case of Joe and His Mother}

Joe is a 45-year-old single man with who has lived with schizophrenia for over 20 years. He is involved in mental health treatment and has been receiving both case management services and antipsychotic medication. Joe's father died when he was young, and he has lived alone with his mother ever since. At times, Joe has paranoid delusions involving his mother, e.g., that she causes him to smell foul odors. Joe has told his psychiatrist that he feels both rage toward his mother for bringing him into the world with a psychiatric disability along with fears that she might abandon him eventually because of his mental illness. When he tells his mother how he feels, she tends to either belittle or ignore his concerns, which upsets Joe and makes him feel disrespected. After these conversations, he sometimes experiences strong urges to physically attack his mother and he has assaulted her several times. At other times, Joe has voluntarily presented himself to the local county mental health emergency service asking for hospitalization to prevent him from hurting his mother.

\section{Most Recent Violent Incident}

Joe was eating breakfast with his mother and she told him to take out the garbage after he finished eating. Joe refused, saying that she poisoned the garbage and if he took it out, he would be poisoned. She told him he was being ridiculous and insisted he take out the garbage. Joe and his mom got into a heated argument about how he is frequently unwilling to help with the housework, and she tried to pull him out of his chair (which was near impossible because Joe weighs 
over $300 \mathrm{lbs}$.). Joe became angry and hit his mother, causing her to fall to the floor. His mother then told him to leave the house and never come back. When he refused, she called the police, and he was taken to the psychiatric emergency admissions unit for evaluation.

\section{Analysis of the Composite Case}

This illustrates several issues we identified earlier regarding two explanations for family violence by persons with SMI. As a result of his psychiatric symptoms (i.e., delusions regarding foul odors and being poisoned by the household garbage), Joe believed his mother intended to harm him. Joe's anger in relation to the incident reflect his emotion regulation problems, specifically regarding anger, which led to behavioral dyscontrol, i.e., hitting his mother. When the crisis social worker evaluated Joe after the police brought him to the admissions unit, he admitted he had not attended his medication clinic appointment, thereby missing his biweekly prolixin decanoate injection and was not taking his oral antipsychotic medication. In addition, he had stopped attending partial hospitalization. Thus, he had not been receiving psychiatric treatment that could have mitigated his symptoms and provided him with counseling support where he could have discussed the ongoing conflict with his mother. During the most recent incident of violence, Joe and his mother also had discordant personal agendas. Joe's mother wanted him to take out the garbage. Joe, however, wanted to not take out the garbage as he perceived doing so would result in him being poisoned. Upon his mother continuing to advance her personal agenda, Joe responded by hitting her. When Joe's mother spoke with the crisis social worker, she told the social worker that although she loved her son, she found the ongoing caregiving to be burdensome and exhausting. The living situation involved only the two of them, and there was daily interpersonal contact resulting in ongoing conflict.

\section{Intervening to Prevent Acts of Violence}

Regular meetings between a clinical social worker, Joe, and his mother addressing the topics we have recommended (mutual understanding; positive communication; effective problem-solving; symptoms and psychiatric crises; triggers to, and early warning signs of, anger and conflict; and strategies for de-escalating conflict and managing violent behavior), could be very helpful in preventing incidents of violence. Educating Joe and his mother on treatment services and supporting them in accessing such services (a component of addressing symptoms and psychiatric crises) many have resulted in Joe better engaging in mental health treatment and decreasing the symptoms that contributed to the most recent incident of violence. Joe could have more calmly explained to his mother that he did not want to take out the garbage because he feared he would be poisoned and could have volunteered to complete a different household chore instead (related to the topics of positive communication and effective problem-solving). During the argument, Joe could have identified that he was experiencing physiological and cognitive warning signs that his anger was escalating, and he could have acted to moderate his anger and prevent violence, such as utilizing positive self-talk or proposing the use of a "time-out" from the argument (as a result of having identified early warning signs of anger and strategies for de-escalating conflict and preventing violence). When Joe refused to take out the garbage due to fears of being poisoned, his mother could have considered not further advancing her request verbally (related to the topics of effective problem-solving and understanding psychiatric symptoms), nor attempting to pull Joe out of his chair (as a result of having identified triggers to Joe's anger and violence). Instead, Joe's mother could have talked with him about his fears and reassured him that she is not attempting to poison him (related to addressing positive communication and understanding psychiatric symptoms).

\section{Conclusion}

The COVID-19 pandemic is resulting in unprecedented challenges to the health and wellbeing of individuals and families, which are disproportionately being experienced by disadvantaged populations. It is critical that during the pandemic social workers and other human service professionals assist disadvantaged populations in preventing negative outcomes and enhancing their wellbeing. Persons with SMI and their families are disadvantaged populations often overlooked, and we implore clinicians to engage with members of these populations to prevent family conflict and violence and strengthen relationship quality. The COVID-19 pandemic has revealed the stark unmet needs experienced by many disadvantaged populations prior to the pandemic, which have only been exacerbated since the pandemic's onset. While it is particularly critical that practitioners intervene to prevent violence by persons with SMI toward family members during the pandemic, it is also important that such interventions continue to be offered beyond the pandemic. In this article, we have presented recommendations-based on extant evidence-for how clinicians may effectively intervene to prevent family violence by this population. We consider these recommendations to be valuable during the COVID-19 pandemic and into the foreseeable future. An established clinical intervention effective at preventing this phenomenon is sorely needed, with a novel extension of family psychoeducation likely being one such intervention. Finally, evidence tentatively suggests that much family 
violence by persons with SMI may be bidirectional (Labrum et al., 2020). As such, the effectiveness of interventions in this area should be researched regarding decreasing family violence both by and toward persons with SMI.

Funding The authors did not receive funding related to this manuscript.

\section{Declarations}

Conflict of interest The authors declare that they have no conflicts of interest.

\section{References}

Ahn, B. H., Kim, J. H., Oh, S., Choi, S. S., Ahn, S. H., \& Kim, S. B. (2012). Clinical features of parricide in patients with schizophrenia. Australian \&amp; New Zealand Journal of Psychiatry, 46, 621-629.

Allen, C. M., \& Straus, M. A. (1980). Resources, power, and husbandwife violence. In M. A. Strauss \& G. T. Hotaling (Eds.), Social causes of husband-wife violence. University of Minnesota Press.

Askola, R., Louheranta, O., Soininen, P., Putkonen, H., Åstedt-Kurki, P., \& Paavilainen, E. (2017). The offense as perceived by the parents of forensic psychiatric patients. Issues in Mental Health Nursing, 38, 705-711.

Awad, A. G., \& Voruganti, L. N. (2008). The burden of schizophrenia on caregivers. PharmacoEconomics, 26, 149-162.

Binder, R. L., \& McNeil, D. E. (1986). Victims and families of violent psychiatric patients. The Bulletin of the American Academy of Psychiatry and the Law, 14, 131-139.

Boserup, B., McKenney, M., \& Elkbuli, A. (2020). Alarming trends in US domestic violence during the COVID-19 pandemic. The American Journal of Emergency Medicine, 38, 2753-2755. https://doi.org/10.1016/j.ajem.2020.04.077

Copeland, D. A., \& Heilemann, M. V. (2011). Choosing "the best of the hells": Mothers face housing dilemmas for their adult children with mental illness and a history of violence. Qualitative Health Research, 21, 520-533.

Czeisler, M. É., Lane, R. I., Petrosky, E., Wiley, J. F., Christensen, A., Njai, R., \& Czeisler, C. A. (2020). Mental health, substance use, and suicidal ideation during the COVID-19 pandemic-United States, June 24-30, 2020. Morbidity and Mortality Weekly Report, 69, 1049-1057.

Darmedru, C., Demily, C., \& Franck, N. (2017). Cognitive remediation and social cognitive training for violence in schizophrenia: A systematic review. Psychiatry Research, 251, 266-274.

Desmarais, S. L., Van Dorn, R. A., Johnson, K. L., Grimm, K. J., Douglas, K. S., \& Swartz, M. S. (2014). Community violence perpetration and victimization among adults with mental illnesses. American Journal of Public Health, 104, 2342-2349.

Dollard, J., Miller, N. E., Doob, L. W., Mowrer, O. H., \& Sears, R. R. (1939). Frustration and aggression. Yale University Press. https:// doi.org/10.1037/10022-000

Elbogen, E. B., Swanson, J. W., Swartz, M. S., \& Dorn, R. V. (2005). Family representative payeeship and violence risk in severe mental illness. Law and Human Behavior, 29(5), 563-574.

Estroff, S. E., Swanson, J. W., Lachicotte, W. S., Swartz, M., \& Bolduc, M. (1998). Risk reconsidered: Targets of violence in the social networks of people with serious psychiatric disorders. Social Psychiatry and Psychiatric Epidemiology, 33, S95-S101.
Fazel, S., Gulati, G., Linsell, L., Geddes, J. R., \& Grann, M. (2009). Schizophrenia and violence: systematic review and meta-analysis. PLoS Med, 6(8), e1000120.

Fazel, S., Lichtenstein, P., Grann, M., Goodwin, G. M., \& Långström, N. (2010). Bipolar disorder and violent crime: New evidence from population-based longitudinal studies and systematic review. Archives of General Psychiatry, 67, 931-938.

Fleischman, A., Werbeloff, N., Yoffe, R., Davidson, M., \& Weiser, M. (2014). Schizophrenia and violent crime: A populationbased study. Psychological Medicine, 44, 3051-3057.

Gelles, R. J., \& Straus, M. A. (1979). Determinants of violence in the family: Toward a theoretical integration. In W. R. Burr, R. Hill, F. I. Nye, \& I. L. Resiss (Eds.), Contemporary theories about the family (pp. 549-581). Free Press.

Hamada, K., \& Fan, X. (2020). The impact of COVID-19 on individuals living with serious mental illness. Schizophrenia Research, $222,3-5$.

Harvey, C. (2018). Family psychoeducation for people living with schizophrenia and their families. Bjpsych Advances, 24, 9-19.

Haselden, M., Brister, T., Robinson, S., Covell, N., Pauselli, L., \& Dixon, L. (2019). Effectiveness of the NAMI homefront program for military and veteran families: In-person and online benefits. Psychiatric Services, 70, 935-939.

Hsu, M. C., \& Tu, C. H. (2014). Adult patients with schizophrenia using violence towards their parents: A phenomenological study of views and experiences of violence in parent-child dyads. Journal of Advanced Nursing, 70, 336-349.

Johnson, M. P. (2008). A typology of domestic violence: Intimate terrorism, violent resistance, and situational couple violence. Northeastern University.

Kageyama, M., Yokoyama, K., \& Horiai, Y. (2019). Perceptions of stages of family violence and their perceived solutions in persons with schizophrenia. The Open Nursing Journal, 13, $156-167$.

Kageyama, M., Yokoyama, K., Horiai, Y., \& Solomon, P. (2020). Pilot study of a video-based educational program to reduce family violence for parents of adult children with schizophrenia. Psychiatric Quarterly, 91, 547-560.

Kageyama, M., Yokoyama, K., Nakamura, Y., Kobayashi, S., \& Fujii, C. (2018). The coping process of Japanese parents who experience violence from adult children with schizophrenia. Archives of Psychiatric Nursing, 32, 549-554.

Kaplan, K., Solomon, P., Salzer, M. S., \& Brusilovskiy, E. (2014). Assessing an Internet-based parenting intervention for mothers with a serious mental illness: A randomized controlled trial. Psychiatric Rehabilitation Journal, 37, 222-231.

Katz, J., Medoff, D., Fang, L. J., \& Dixon, L. B. (2015). The relationship between the perceived risk of harm by a family member with mental illness and the family experience. Community Mental Health Journal, 51, 790-799.

Kivisto, A. J., \& Watson, M. E. (2016). 12-Month prevalence, trends, gender differences, and the impact of mental health services on intimate partner violence perpetration among discharged psychiatric inpatients. Journal of Family Violence, 31, 379-385.

Kolko, D. J., Brown, E. J., Shaver, M. E., Baumann, B. L., \& Herschell, A. D. (2011). Alternatives for families: A cognitivebehavioral therapy: Session guide (3rd ed.). University of Pittsburgh School of Medicine.

Labrum, T. (2017). Factors related to abuse of older persons committed by relatives with psychiatric disorders. Archives of Gerontology and Geriatrics, 68, 126-134.

Labrum, T. (2018). Caregiving for relatives with psychiatric disorders vs. co-occurring psychiatric and substance use disorders. Psychiatric Quarterly, 89, 631-644.

Labrum, T., \& Solomon, P. L. (2015). Physical elder abuse perpetrated by relatives with serious mental illness: A preliminary 
conceptual social-ecological model. Aggression and Violent Behavior, 25, 293-303.

Labrum, T., \& Solomon, P. L. (2016). Factors associated with family violence by persons with psychiatric disorders. Psychiatry Research, 244, 171-178.

Labrum, T., \& Solomon, P. L. (2017). Rates of victimization of violence committed by relatives with psychiatric disorders. Journal of Interpersonal Violence, 32(19), 2955-2974.

Labrum, T., \& Solomon, P. L. (2018). Safety fears held by caregivers regarding relatives with psychiatric disorders. Health \&amp; Social Work, 43, 165-174.

Labrum, T., \& Solomon, P. (2022). Serious mental illness and incidents between adult children and parents responded to by police. Psychological Medicine, 52, 102-111. https://doi.org/10.1017/ S0033291720001762

Labrum, T., Solomon, P. L., \& Marcus, S. C. (2020). Victimization and perpetration of violence involving persons with mood and other psychiatric disorders and their relatives. Psychiatric Services, 71, 498-501.

Labrum, T., Walk, M., \& Solomon, P. L. (2016). Measuring limitsetting practices used by family members towards relatives with psychiatric disorders. Psychiatric Quarterly, 87, 465-477.

Labrum, T., Zingman, M. A., Nossel, I., \& Dixon, L. B. (2021). Violence by persons with serious mental illness toward family caregivers and other relatives: A review. Harvard Review of Psychiatry, 29, 10-19.

Linehan, M. M. (2014). DBT skills training handouts and worksheets. Guilford Publications.

Love, H. A., Spencer, C. M., May, S. A., Mendez, M., \& Stith, S. M. (2020). Perpetrator risk markers for intimate terrorism and situational couple violence: A meta-analysis. Trauma, Violence, \&amp; Abuse, 21, 922-931.

Lucksted, A., McFarlane, W., Downing, D., \& Dixon, L. (2012). Recent developments in family psychoeducation as an evidence-based practice. Journal of Marital and Family Therapy, 38, 101-121.

Monahan, J., Steadman, H. J., Silver, E., Appelbaum, P. S., Robbins, P. C., Mulvey, E. P., Roth, L. H., Grisso, T., \& Banks, S. (2001). Rethinking risk assessment: The MacArthur study of mental disorder and violence. Oxford University Press.

National Alliance for Caregiving. (2016). On pins and needles: Caregivers of adults with mental illness. National Alliance for Caregiving. https://www.caregiving.org/wp-content/uploads/2020/ 05/NAC_Mental_Illness_Study_2016_FINAL_WEB-1.pdf. Retrieved 1 Oct 2021.

Newhill, C. E., Eack, S. M., \& Mulvey, E. P. (2012). A growth curve analysis of emotion dysregulation as a mediator for violence in individuals with and without borderline personality disorder. Journal of Personality Disorders, 26, 452-467.

Onwumere, J., Parkyn, G., Learmonth, S., \& Kuipers, E. (2019). The last taboo: The experience of violence in first-episode psychosis caregiving relationships. Psychology and Psychotherapy: Theory, Research and Practice, 92, 1-19.

Onwumere, J., Zhou, Z., \& Kuipers, E. (2018). Informal caregiving relationships in psychosis: Reviewing the impact of patient violence on caregivers. Frontiers in Psychology. https://doi.org/10. 3389/fpsyg.2018.01530

Rampling, J., Furtado, V., Winsper, C., Marwaha, S., Lucca, G., Livanou, M., \& Singh, S. P. (2016). Non-pharmacological interventions for reducing aggression and violence in serious mental illness: A systematic review and narrative synthesis. European Psychiatry, 34, 17-28.

Reilly, P.M., Shopshire, M.S., Durazzo, T.C., \& Campbell, T.A. (2019). Anger management for substance use disorder and mental health clients: Participant workbook. Substance Abuse and Mental Health Services Administration. Retrieved from https://
store.samhsa.gov/product/Anger-Management-for-SubstanceUse-Disorder-and-Mental-Health-Clients-Participant-Workbook/ PEP19-02-01-002. Retrieved 1 Oct 2021.

Reinharth, J., Reynolds, G., Dill, C., \& Serper, M. (2014). Cognitive predictors of violence in schizophrenia: A meta-analytic review. Schizophrenia Research: Cognition, 1, 101-111.

Rotondi, A. J., Anderson, C. M., Haas, G. L., Eack, S. M., Spring, M. B., Ganguli, R., Newhill, C., \& Rosenstock, J. (2010). Web-based psychoeducational intervention for persons with schizophrenia and their supporters: One-year outcomes. Psychiatric Services, 61, 1099-1105.

Smith, L. M., Onwumere, J., Craig, T., \& Kuipers, E. (2018). Caregiver correlates of patient-initiated violence in early psychosis. Psychiatry Research, 270, 412-417. https://doi.org/10.1016/j.psych res.2018.09.011

Solomon, P. L., Cavanaugh, M. M., \& Gelles, R. J. (2005). Family violence among adults with severe mental illness: A neglected area of research. Trauma, Violence, \&amp; Abuse, 6, 40-54. https:// doi.org/10.1177/1524838004272464

Sporer, K., Speropolous, L., \& Monahan, K. E. (2019). Finding the "golden moments": Strategies of perseverance among parents and siblings of persons with severe mental illness and violent tendencies. Journal of Family Issues, 40, 2658-2683.

Straus, M. A. (1979). Measuring intrafamily conflict and violence: The conflict tactics (CT) scales. Journal of Marriage and the Family, $41,75-88$.

Straus, M. A. (2011). Gender symmetry and mutuality in perpetration of clinical-level partner violence: Empirical evidence and implications for prevention and treatment. Aggression and Violent Behavior, 16, 279-288.

Straznickas, K. A., McNiel, D. E., \& Binder, R. L. (1993). Violence toward family caregivers by mentally ill relatives. Psychiatric Services, 44, 385-387.

Substance Abuse and Mental Health Services Administration. (2009). Family psychoeducation: Training frontline staff. Retrieved from https://store.samhsa.gov/sites/default/files/d7/priv/trainingfrontli nestaff-fp_0.pdf. Retrieved 1 Oct 2021.

Substance Abuse and Mental Health Services Administration. (2019). A practical guide to psychiatric advance directives. Retrieved from https://www.samhsa.gov/sites/default/files/a_practical_guide_to_ psychiatric_advance_directives.pdf. Retrieved 1 Oct 2021.

Sun, G. C., \& Hsu, M. C. (2016). Effects of nurse-led child-and parentfocused violence intervention on mentally ill adult patients and victimized parents: A randomized controlled trial. International Journal of Nursing Studies, 60, 79-90.

Truman, J. L., \& Morgan, R. E. (2014). Nonfatal domestic violence, 2003-2012. US Department of Justice. Retrieved from https:// www.bjs.gov/content/pub/pdf/ndv0312.pdf. Retrieved 1 Oct 2021.

Vaddadi, K. S., Gilleard, C., \& Fryer, H. (2002). Abuse of carers by relatives with severe mental illness. International Journal of Social Psychiatry, 48(2), 149-155. https://doi.org/10.1177/00207 6402128783208

Varghese, A., Khakha, D. C., \& Chadda, R. K. (2016). Pattern and type of aggressive behavior in patients with severe mental illness as perceived by the caregivers and the coping strategies used by them in a tertiary care hospital. Archives of Psychiatric Nursing, $30,62-69$.

Wearden, A. J., Tarrier, N., Barrowclough, C., Zastowny, T. R., \& Rahill, A. A. (2000). A review of expressed emotion research in health care. Clinical Psychology Review, 20, 633-666.

Wexler, D. B. (2020). The STOP domestic violence program: Group leader's manual. WW Norton \& Company.

Whiting, D., Lichtenstein, P., \& Fazel, S. (2020). Violence and mental disorders: a structured review of associations by individual 
diagnoses, risk factors, and risk assessment. The Lancet Psychiatry, 8, 150-161.

Witt, K., Van Dorn, R., \& Fazel, S. (2013). Risk factors for violence in psychosis: Systematic review and meta-regression analysis of 110 Studies. PLoS ONE, 8, e55942. https://doi.org/10.1371/journ al.pone. 0055942

Publisher's Note Springer Nature remains neutral with regard to jurisdictional claims in published maps and institutional affiliations.

Travis Labrum is an assistant professor in the School of Social Work at the University of Pittsburgh. His research interests primarily include issues affecting persons with serious mental illness and their families, including violence, caregiving, treatment services, and criminal justice involvement.
Christina Newhill is a professor in the School of Social Work at the University of Pittsburgh with a joint appointment with the Clinical and Translational Science Institute. Her research focuses on community mental health services, psychosocial interventions for individuals with serious and persistent mental illness and their families, and improving the assessment of violent behavior.

Peter Simonsson is a postdoctoral fellow in the Lewis Katz School of Medicine at Temple University. His research focuses on reducing violent and non-violent recidivism among persons with serious mental illness and improving other justice outcomes for this population.

Ana T. Flores is a doctoral student in the School of Social Work at the University of Pittsburgh. Her research interests include psychosocial interventions for people with schizophrenia, implementation of evidence-based practices in community settings, cultural adaptations, and equitable access to mental health services for communities of color. 